Research Paper

\title{
Effects of Red Wine Tannat on Oxidative Stress Induced by Glucose and Fructose in Erythrocytes in Vitro
}

\author{
Camila Eliza Fernandes Pazzini ${ }^{1}$, Ana Ceolin Colpo ${ }^{2}$, Márcia Rósula Poetini ${ }^{1}$, Cauê Ferreira Pires ${ }^{1}$, \\ Vanessa Brum de Camargo 2, Andreas Sebastian Loureiro Mendez 3, Miriane Lucas Azevedo 1, Júlio César \\ Mendes Soares 1, Vanderlei Folmer 2, \\ 1. Universidade Federal do Pampa (UNIPAMPA), campus Itaqui, Rua Joaquim de Sá Brito, s/n, 97650-000, Itaqui, Brasil \\ 2. Universidade Federal do Pampa (UNIPAMPA), campus Uruguaiana, BR 472, Km 592, 97500-970, Uruguaiana, Brasil \\ 3. Universidade Federal do Rio Grande do Sul (UFRGS), Faculdade de Farmácia, Avenida Ipiranga 2752, 90610-000, Porto Alegre-RS, Brazil
}

$\triangle$ Corresponding author: Tel.: +55 55 8111-1104; E-mail: vandfolmer@gmail.com. Present address: Universidade Federal do Pampa (UNIPAMPA), campus Uruguaiana, BR 472, KM 592, 97500-970 - Caixa Postal 118, Uruguaiana, Rio Grande do Sul, Brasil.

(c) 2015 Ivyspring International Publisher. Reproduction is permitted for personal, noncommercial use, provided that the article is in whole, unmodified, and properly cited. See http://ivyspring.com/terms for terms and conditions.

Received: 2015.01.27; Accepted: 2015.02.09; Published: 2015.06.01

\begin{abstract}
The literature indicates that red wine presents in its composition several substances that are beneficial to health. This study has investigated the antioxidant effects of Tannat red wine on oxidative stress induced by glucose and fructose in erythrocytes in vitro, with the purpose to determine some of its majoritarian phenolic compounds and its antioxidant capacity. Erythrocytes were incubated using different concentrations of glucose and fructose in the presence or absence of wine. From these erythrocytes were determined the production of thiobarbituric acid reactive species (TBARS), glucose consumption, and osmotic fragility. Moreover, quantification of total phenolic, gallic acid, caffeic acid, epicatechin, resveratrol, and DPPH scavenging activity in wine were also assessed. Red wine showed high levels of polyphenols analyzed, as well as high antioxidant potential. Erythrocytes incubated with glucose and fructose had an increase in lipid peroxidation and this was prevented by the addition of wine. The wine increased glucose uptake into erythrocytes and was able to decrease the osmotic fragility of erythrocytes incubated with fructose. Altogether, these results suggest that wine leads to a reduction of the oxidative stress induced by high concentrations of glucose and fructose.
\end{abstract}

Key words: Diabetes, antioxidant activity, phenolic compounds, lipid peroxidation, wine.

\section{Introduction}

Oxidative stress occurs when there is an imbalance between pro-oxidants and antioxidants in the organism, so that, the first is predominant, producing toxic or harmful compounds for tissue, denominated free radicals or reactive oxygen species (ROS) [1]. The excess of free radicals induces harmful effects such as lipid peroxidation, damage to DNA, proteins, enzymes and carbohydrate [2]. Studies have shown a strong relationship between hyperglycemia and oxidative stress $[3,4,5,6]$. Consequently, there is a great deal of interest in foods that contain antioxidants and health-promoting phytochemicals as potential therapeutic agents. In this context, several experiments, both in vitro and in vivo, have been conducted with numerous antioxidants components, including polyphenols from red wine $[7,8]$.

This interest in phenolic compounds of wine started in 1992 with the publication of the "French Paradox" theory. In France, there is a high consumption of saturated fats, but mortality from heart disease is a third lower than in the United Kingdom, for example. One of the French habits is drink red wine with their main dishes, and this seems to be an important differential. A research conducted by Renaud and De Longeril [9] observed low mortality from heart disease associated with the consumption of this 
drink. Withehead et al, [10] revealed that the ingestion of $300 \mathrm{~mL}$ red wine, led to an $18 \%$ increase in the serum antioxidant capacity after 1 hour. Moreover, Napoli et al, [11] in a study made from nine diabetic patients, who intake $360 \mathrm{~mL}$ of red wine per day for two weeks, observed an improvement in insulin sensitivity.

Red wine presents in its composition more than 600 phenolic compounds that are beneficial to health. However, the studies are limited primarily to the presence of resveratrol, but other phenolic compounds such as flavonoids, quercetin and catechins, integrated in large quantities the red wine. Furthermore, most studies evaluated the effects of this drink for cardiovascular diseases prevention, making required additional studies to confirm the beneficial effects of red wine in other diseases, such as Diabetes mellitus.

Diabetes mellitus may cause a series of secondary complications, including atherosclerosis, renal failure, cataract, retinopathy, and some others, which are caused by oxidative stress generated by hyperglycemia (Brito and others 2007). So studies using bioactive compounds that may be able to minimize this process, are relevant. Thus, the aim of the present study was to observe the antioxidant effect of Tannat red wine (vintage 2006) produced in Itaqui - RS Brazil, according to oxidative stress induced by glucose and fructose in erythrocytes in vitro, in addition to determine some of its majoritarian phenolic compounds (gallic acid, caffeic acid, epicatechin and resveratrol) and their antioxidant capacity.

\section{Materials and Methods}

\section{Red wine samples}

Red wine used in this study was the Tannat (2006 vintage), containing 13\% (v/v) ethanol, provided by a winery, located in Itaqui (Rio Grande do Sul - Brazil).

\section{Chemicals}

Thiobarbituric acid (TBA), malonaldehyde-bis-dimethyl acetal (MDA), 2,2-diphenyl-1picrylhydrazyl (DPPH), caffeic acid, gallic acid, epicatechin and resveratrol were purchased from Sigma Aldrich (St. Louis, MO, USA). Folin-Ciocalteau's phenol reagent was obtained from Merck (Darmstadt, Germany).

\section{Preparation of erythrocytes}

Discarded blood bags have been donated by transfusion agency located São Patricio Hospital, Itaqui, Brazil. The experimental protocol of this study was approved by the Ethics Committee of the Universidade Federal do Pampa (number 002 2012).
The test tubes containing $2.5 \mathrm{~mL}$ of erythrocytes were centrifuged at 2,000 $\mathrm{g}$ for five minutes and the supernatant was replaced by saline solution $0.9 \%$ $\mathrm{NaCl}$ in the same proportion. This procedure was performed twice, after, the red blood cells where resuspended with a hematocrit $50 \%$ (erythrocyte suspension: solution $0.9 \% \mathrm{NaCl}, \mathrm{v} / \mathrm{v}$ ), and fructose or glucose concentrations corresponding to 5, 10, 30 and $100 \mathrm{mM}$, in $100 \mathrm{mM}$ Tris- $\mathrm{HCl}$ buffer (pH 7.4). These values were defined based on other studies that investigate the effects of high glucose and fructose concentrations in vitro $[12,13]$.

Erythrocytes were incubated at $37{ }^{\circ} \mathrm{C}$ for 24 hours in the presence or absence of red wine in amounts of $0.075,0.15$ and $0.225 \mathrm{~mL}$ of wine/ $\mathrm{mL}$ incubated erythrocytes. This corresponds to $0.33,0.66$ and $0.99 \mathrm{mg} / \mathrm{L} \mathrm{GAE}$ of total polyphenols, conforming to the respective of wine volumes used. The wine quantities used were calculated based on a wine consumption of 150, 300 and $450 \mathrm{~mL}$ (one, two and three glasses, respectively) for an adult man (average body weight of $70 \mathrm{~kg}$ ) containing around 5 liters of blood circulating in his body. So, we made a linear interpolation to calculate the amount of wine being incubated with $2.5 \mathrm{~mL}$ of erythrocytes.

According to the World Health Organization (WHO) [14] the moderate wine consumption (one or two glasses) represents low risk for the onset diseases. This explains the volumes used in our study (lower, intermediate and higher volume of wine).

\section{Evaluation of lipid peroxidation}

Production of thiobarbituric acid reactive species (TBARS) was determined according to Ohkawa et al, [15]. Briefly, after washing erythrocytes with $0.9 \%$ $\mathrm{NaCl}$ twice, the samples, containing glucose or fructose, added or not of red wine in the volumes described above, were precipitated with $40 \%$ acetic acid in the ratio 1:2 and centrifuged at 2,000 $\mathrm{g}$ for separating from the supernatant. The amount TBARS produced was measured in spectrophotometer Biospectro UV-Vis, model SP-220 (Curitiba, PR, Brazil), at 532 $\mathrm{nm}$, using malondialdeide (MDA) to construct standards curves.

\section{Quantification of glucose uptake}

The quantification of glucose uptake is based on the disappearance of glucose in erythrocytes quantitated before and after incubation for 24 hours. We used a glucose oxidase enzymatic colorimetric kit (Labtest, Minas Gerais, Brazil).

\section{Osmotic fragility test}

After incubation of the erythrocytes with the same concentration of glucose or fructose $(5,10,30$ and $100 \mathrm{mM})$ and red wine $(0.075,0.15$ and $0.225 \mathrm{~mL}$ 
of wine/mL incubated erythrocytes) were washed with $150 \mathrm{mM} \mathrm{NaCl}$ solution (twice) and tested for osmotic fragility. The resistance of erythrocytes to hemolysis was evaluated by measuring as a function of decreasing $\mathrm{NaCl}$ concentration. According to Fernandez and Fink [16] it was determined the concentration of hemoglobin in the supernatant using a commercial kit (Labtest, Minas Gerais, Brazil).

In order to discard the interference of phenolic compounds in preventing the hemoglobin oxidation by cyanide of the Drabkin's solution, an assay was performed measuring hemoglobin from erythrocytes incubated with wine, adding $0.5 \mathrm{mM}$ of hydrogen peroxide plus $2.5 \mathrm{mM}$ of sodium azide.

\section{Determination of phenolics in wine}

The concentration of total polyphenols was determined by the colorimetric method of Folin-Ciocalteau described by Singleton and Rossi [17]. The concentration of phenolic compounds was expressed as gallic acid equivalents (GAE). UV-Vis absorbance was measured in a Perkin Elmer Lambda 35 UV/Vis Double array Spectrophotometer (Norwalk, $\mathrm{CT}$, United Sates) with 1-cm quartz cells. The anthocyanins were evaluated by the method described by Lee and Francis [18] with modifications, conducting readings in a spectrophotometer Biospectro UV-Vis model SP-220 (Curitiba, PR, Brazil) at $520 \mathrm{~nm}$, results were expressed in $\mathrm{mg} / \mathrm{L}$ of wine.

Caffeic acid, gallic acid, epicatechin, and resveratrol were also quantified by HPLC in a Prominence Liquid Chromatograph Shimadzu (Shimadzu Corporation, Kyoto, Japan) equipped with a LC-20AT pump, a SIL-20A auto sampler, a SPD-20AT PDA detector and a CTO-20A column oven. LC Solution V. 1.24 SP1 system software was used to control the equipment and to obtain data and responses from the LC system.

A reversed phase ODS-Hypersil Thermo Scientific C18 column $(250 \times 4.6 \mathrm{~mm}$ i.d., $5-\mu \mathrm{m}$ particle size $)$ (Bellefonte, United States) was used for chromatographic separation. The analyses were performed according to the procedure previously described by Quirós et al, [19] in a gradient elution mode with a 0.8 $\mathrm{mL} / \mathrm{min}$ flow, employing two mobile phases: A (water/acetonitrile/acetic acid, 67:32:1, v/v/v) and B (water/acetic acid, 99:1, v/v). The gradient profile was $0-4 \mathrm{~min}, 20-30 \% \mathrm{~A}$ and $80-70 \% \mathrm{~B} ; 4-8 \mathrm{~min}, 30-40 \%$ $\mathrm{A}$ and $70-60 \% \mathrm{~B} ; 8-12 \mathrm{~min}, 40-65 \% \mathrm{~A}$ and $60-35 \% \mathrm{~B}$; 12-16 $\mathrm{min}, 65-80 \% \mathrm{~A}$ and $35-20 \% \mathrm{~B}$; $16-20 \mathrm{~min}, 80-95 \%$ $\mathrm{A}$ and $20-5 \% \mathrm{~B} ; 20-22 \mathrm{~min}, 95-97 \% \mathrm{~A}$ and $5-3 \% \mathrm{~B} ; 22-24$ min, $97-100 \% \mathrm{~A}$ and $3-0 \% \mathrm{~B}$; and $24-35 \mathrm{~min}, 100 \% \mathrm{~A}$, followed by re-equilibration of the column for $5 \mathrm{~min}$. Detection was performed at $280 \mathrm{~nm}$. The injection volume was $20 \mu \mathrm{L}$ and all analyses were conducted at
$25 \pm 1^{\circ} \mathrm{C}$.

For standard preparation, gallic acid, caffeic acid, epicatechin, and resveratrol were dissolved in ethanol and mixed to obtain a solution containing gallic acid at $120.0 \mu \mathrm{g} / \mathrm{mL}$ and other standards at $200.0 \mu \mathrm{g} / \mathrm{mL}$. For wine analysis, the samples were injected directly, as marketed. All solutions were filtered through a $0.45-\mu \mathrm{m}$ membrane filter from Millipore (Milford, MA, United States) before injection. The quantitation of compounds is also based on some references applied to wine samples, whose concentration range and limits of detection and quantitation were established $[20,19,21,22]$.

\section{DPPH radical scavenging assay}

Free radical scavenging activities of wine were measured by the DPPH assay described by Brand-Williams et al, [23]. A volume of $100 \mathrm{~mL}$ of red wine was added to $3.9 \mathrm{~mL}$ of methanol solution of $\mathrm{DPPH}$. The tubes were agitated and kept in the dark for $30 \mathrm{~min}$ before reading at $517 \mathrm{~nm}$ in a spectrophotometer Biospectro UV-Vis, model SP-220 (Curitiba, PR, Brazil).

The antioxidant capacity was represented as \% radical scavenging capacity (RSC) remaining after 30 min of reaction according to the following equation:

\section{\%RSC: Absorbance of control - Absorbance of sample * 100 Absorbance of control}

where absorbance of control represents the absorbance of the DPPH solution alone measured at zero time, and absorbance of sample is the absorbance for each sample $30 \mathrm{~min}$ after the addition of the DPPH solution.

\section{Statistical analysis}

Graphpad Prism 5 software was used for statistical analysis and for plotting graphs. The results were analyzed using one-way ANOVA. Differences between groups were determined using Bonferroni's post hoc test. Differences were considered statistically significant at $p<0.05$. All data are reported as mean \pm standard deviation (S.D.).

\section{Results and discussion}

\section{Polyphenols, phenolic compounds and free radical scavenging (DPPH)}

Red wines made from Vitis vinifera cv. Tannat grapes, are known to possess high contents of tannins and have an intense color due to the presence of pigments such as anthocyanins [24]. The concentration of total anthocyanins found in this study was 107.2 $\mathrm{mg} / \mathrm{L}$ (Table 1). Concentration lower than observed by Zocche [25], who used similar methodology to our study with cv. Tannat wines (2008 vintage) of Rio 
Grande do Sul, whose concentration obtained was $667.36 \mathrm{mg} / \mathrm{L}$. This fact may be explained by the wine age investigated, because anthocyanins are responsible for the intense color of young red wines. Meanwhile, they are combined among themselves or with other tannins present in wine, producing larger molecules that tend to precipitate over time. Thus, the wines will become less stained, acquiring a brownish red tint $[27,26]$. Another study carried out by McRae et al, [27] investigated the color parameters, concentrations of tannins and anthocyanins, and tannins composition of a 50 year series of Cabernet Sauvignon wines from Australia confirmed this effect. They found a concentration of anthocyanins less than 200 $\mathrm{mg} / \mathrm{L}$ for wines with age of 5 years and $627 \mathrm{mg} / \mathrm{L}$ for younger wine.

The concentration of total polyphenols is also shown in Table 1. Tannat wine contained high concentration of total phenolics $(4,410 \mathrm{mg} / \mathrm{L} \mathrm{GAE})$ and, this concentration was greater than obtained by Freitas [28] in his study with Tannat wines from Bento Gonçalves (RS, Brazil), whose value obtained was 2,282.2 mg/L GAE. Polyphenols are responsible for protecting plants from physical attacks, as the sun's ultraviolet radiation and biological attacks by fungi, bacteria and viruses, and they are distributed in the leaves, seed and the grapes skin. Its concentration in the wine depends on several factors including the grape variety, weather conditions, grapes cultivation techniques and winemaking [1]. A factor that may have favored the biosynthesis of polyphenols in the Campaign Gaúcha is that during budding and flowering of wines the days are sunny, dry and there is little precipitation, unlike Bento Gonçalves, were this period is characterized by exacerbated rain. This explains the high concentrations of polyphenols found in the analyzed wine.

Table 1: Polyphenolic constituents and free radical scavenging (DPPH) of the red wine Tannat (vintage 2006).

\begin{tabular}{ll}
\hline Total Polyphenols $^{a}$ & $4,410 \mathrm{mg} / \mathrm{L} \mathrm{GAE}$ \\
\hline Total Anthocyanins $^{b}$ & $107.2 \mathrm{mg} / \mathrm{L}$ \\
Gallic Acid $^{c}$ & $12.63 \mathrm{mg} / \mathrm{L}$ \\
Caffeic Acid $^{c}$ & $7.81 \mathrm{mg} / \mathrm{L}$ \\
Epicatechin $^{c}$ & $26.55 \mathrm{mg} / \mathrm{L}$ \\
Resveratrol $^{c}$ & $9.08 \mathrm{mg} / \mathrm{L}$ \\
DPPH $^{d}$ & $71 \%$ \\
\hline
\end{tabular}

a Method of Folin-Ciocalteau; ${ }^{\circ}$ Lee \& Francis (1972); c HPLC; d DPPH assay

The chromatogram illustrated in Figure 1 shows the presence of gallic acid, caffeic acid, epicatechin, and resveratrol, identified by their retention times (about 6, 20, 21, and 30 minutes for 1, 2, 3, and 4 respectively) . Among phenolics, epicatechin (26.55 $\mathrm{mg} / \mathrm{L})$ and gallic acid $(12.63 \mathrm{mg} / \mathrm{L})$ were identified as major compounds whereas, resveratrol $(9.08 \mathrm{mg} / \mathrm{L})$ and caffeic acid $(7.81 \mathrm{mg} / \mathrm{L})$ showed a minor contribution in this wine (Table 1). Epicatechins are responsible for astringency, bitterness and the body of wine as well as gallic acid antioxidant properties, antimicrobial and antimutagenic $[29,1]$. Similar results were found by Fanzone et al, [30] obtaining values between 15.6-20.9 mg/L of gallic acid and 21.1-30.8 $\mathrm{mg} / \mathrm{L}$ of epicatechin for Argentinian Cabernet Sauvignon wines.
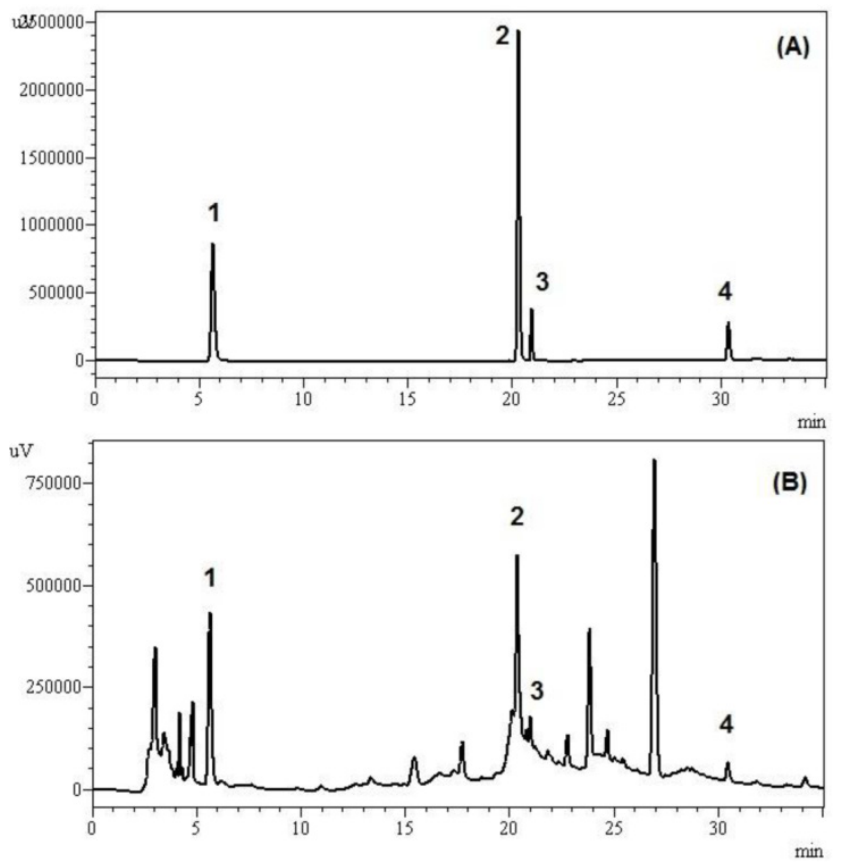

Figure 1: HPLC chromatograms (detection at $280 \mathrm{~nm}$ ) showing the polyphenolic constituents detected in Tannat red wine (vintage 2006). (A) Chromatogram of standards; (B) chromatogram of polyphenolic constituents detected in wine. Peak identification: (1) gallic acid; (2) caffeic acid; (3) epicatechin; (4) resveratrol.

Recently, caffeic acid and its derivatives have attracted considerable attention because of their biological activity and pharmacological properties including antioxidative activities, such as metal chelating capacity [31]. Study has also confirmed that caffeic acid has a copigmentation effect on anthocyanin and that the antioxidant activity of the complex anthocyanin, caffeic acid, was greater than the antioxidant activity of the anthocyanin alone [32]. The concentration of caffeic acid found in this study was similar to the concentration found by Fanzone et al [30], for Argentine wines.

Finally, we reference resveratrol, a polyphenol mostly studied in recent years, and noticed in considerable concentrations $(9.08 \mathrm{mg} / \mathrm{L})$ in the wine analyzed. It is synthesized in grape skins in response to stress caused by fungal attack, mechanical damage or ultraviolet irradiation; moreover the incidence of sunlight and little rainfall are climatic factors with 
marked performance in formation, content and class of resveratrol [33]. Souto et al, [34] quantified, using high performance liquid chromatography, the concentration of trans-resveratrol of 36 red wines samples produced in southern Brazil and found a concentration between $0.82-5.75 \mathrm{mg} / \mathrm{L}$, being the highest concentration for Sangiovese wine.

Importantly, the lack of studies correlating the phenolic compounds present in red wine with situations of hyperglycemia in vitro or in vivo. From the few studies, a large part investigates the effect of resveratrol on Diabetes Mellitus. Szkudelska and Szkudelski [35] verified that the use of resveratrol for a long time decreased the blood glucose in diabetic animals and, interestingly, this compound did not affect glucose levels in animals with normal glycemic level. Venturini et al, [36] in a red wine study (Merlot varietal) containing $3.2 \mu \mathrm{g} / \mathrm{ml}$ resveratrol, observed that the red wine provoked antioxidant effect in hippocampus of diabetic rats.

Summarizing, Tannat wine showed good concentrations of polyphenols and a possible explanation for this may be climatic conditions conducive to grape growing, as low winter temperatures, which favors the growth of these vines, low rainfall and sunny days with temperatures above $18^{\circ} \mathrm{C}$ in fall, which favors flowering [37]. Between all of these climatic factors, the most preponderant, for the development of the grape berry, is sunlight. It influences the synthesis of a key enzyme in the production of phenolic compounds, phenylalanine amonioliase - PAL. This enzyme has its activity increased in vegetables exposed to stressful situations such as water deficit and incidence of sunlight [33]. In fact, in 2006, the weather in Rio Grande do Sul was characterized by summer with high temperatures, severe drought and rigorous winter [38].

Finally, the radical scavenging activity of the wine was tested using the DPPH assay and was observed that the antioxidant capacity of wine was $71 \%$ (Table 1). In accordance to the classification described by Melo et al, [39], there is a strong antioxidant capacity when the percentage of radical scavenging activity exceeds $70 \%$.

In a study with 73 red wines of five Vitis vinifera red grape varieties (Merlot, Malbec, Pinot Noir, Cabernet Sauvignon, and Syrah) from South America, Granato et al, [40] using also the method of DPPH, observed the highest antioxidant activity for the Cabernet Sauvignon from Brazil (66.44\%), Syrah from Argentina (64.12\%) and Malbec from Chile (66.70\%).

Our objectives are not to establish a correlation between the phenolic constituents of Tannat wine and its antioxidant capacity because we believe that this good antioxidant potential of the analyzed wine is due to the set of all polyphenols.

\section{Lipid peroxidation assay}

Lipid peroxidation occurs when there is a metabolic imbalance allowing ROS attack polyunsaturated fatty acids in cell membranes. This mechanism results in changes of the membrane lipids and this loses its architectural features to become firmer and less flexible. With this, appear "ionic cracks" which alter the membrane permeability and enhances the indiscriminate flow of metabolites and cellular debris. The degree of phospholipids peroxidation can be determined by the concentrations of malondialdehyde (MDA) and the method commonly employed is the thiobarbituric acid reactive substances (TBARS) [2].

Erythrocytes have high polyunsaturated fatty acids contained in their membranes, and possess high hemoglobin concentration. These characteristics make human erythrocytes a good field of reference for the study of biomembranes oxidation [41,6] demonstrating that ROS' attack to the erythrocyte membrane induces oxidation of lipids and proteins, and leads to hemolysis [42].

In our study lipid peroxidation in erythrocytes was induced with glucose or fructose. The high glucose and fructose concentration resulted in a significant increase in erythrocytes TBARS levels $(p<0.05)$ when compared to erythrocytes incubated with $5 \mathrm{mM}$ glucose or fructose (physiological condition) (Figure $2 \mathrm{~A}$ and B). Similar result was observed by Salgueiro et al, [6] in human erythrocytes incubated with high glucose concentrations ( 250 and $500 \mathrm{mM}$ ), at both 24 and 48 hours incubation, and Soares et al [13], in research on ebselen and its modification in hemoglobin glycation and osmotic fragility of blood at high concentrations of glucose or fructose. It has also been shown that the auto-oxidation of glucose is an important source of free radicals in Diabetes Mellitus $[43,3,44]$. In this study, this additional source of free radicals generated by hyperglycemia is a plausible contributing factor to the increased of TBARS levels. In addition, increased glucose levels (above $9 \mathrm{mM}$ ) activate the polyol pathway that leads to a depletion of NADPH, which is highly detrimental to the erythrocyte [13].

The addition of different wine volumes provoked a significant decrease $(p<0.05)$ in MDA levels of erythrocytes incubated with glucose (Figure 2A). However, for the erythrocytes incubated with fructose, this effect was only observed for high fructose concentrations (30 and $100 \mathrm{mM}$ ) (Figure 2B). We can infer that red wine could prevent lipid peroxidation caused by hyperglycemia. This advantage was observed until the lowest wine volume used $(0.075 \mathrm{~mL})$, which can be considered a positive factor, since ex- 
aggerated consumption of alcoholic beverages can be detrimental. Similar results were observed for Montilla et al, [7] in experiments with diabetic Wistar rats streptozotocin induced, and the protective effect of red wine Montilla-Moriles on oxidative stress. This red wine protective effect may be related to their high content of polyphenols, which can interact with membranes or reduce/counteract the formation of ROS [6].

\section{Effect of wine on erythrocytes incubated with glucose}

Figure 3A shows the glucose uptake before and after incubation of erythrocytes with glucose during 24 hours at concentrations of 5, 10, 30 and $100 \mathrm{mM}$. According to Habib and Othman [5], the glucose is transported into erythrocytes by facilitated diffusion.

In Figure 3A can be seen that after 24 hours there is a significant reduction $(p<0.05)$ in the concentration of glucose in erythrocytes incubated with 5 and $10 \mathrm{mM}$ of glucose. This fact was not observed in erythrocytes incubated with 30 and $100 \mathrm{mM}$ of glucose. One possible explanation is that chronic hyperglycemia causes many changes in erythrocytes, such as reduced life time, low deformability, aggregation of red cells increased, reduction of cholesterol and sialic acid of membrane [45]. Such changes can affect glucose uptake by erythrocytes. These alterations suffered by the erythrocytes in hyperglycemic conditions may be attributed to oxidative stress, which may lead to lipid peroxidation and osmotic fragility in vitro [45]. Another point to be discussed, in order to better understand, is that the lipid peroxidation and accumulation of MDA can disturb organization of phospholipids in the erythrocyte membrane bilayer, which may lead to a decrease in glucose uptake by erythrocytes and, therefore, increase the glucose level in

A

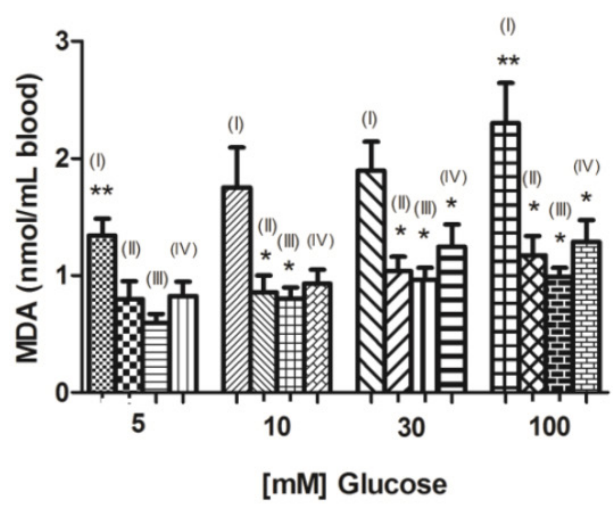

plasma [2].

Figure 3B shows the glucose uptake after incubation of erythrocytes with glucose concentrations of $5,10,30$ and $100 \mathrm{mM}$ added to $0.075 \mathrm{~mL}$ of red wine. A significant decrease $(p<0.05)$ can be observed in glucose concentration in erythrocytes incubated with $100 \mathrm{mM}$ of glucose in the presence of red wine. So, we can infer that the consumption of glucose by the erythrocytes incubated with high concentration of glucose was reestablished, i.e., the wine was able to prevent the inhibition of glucose uptake in erythrocytes. Erythrocytes added with the other volumes of wine $(0.15$ and $0.225 \mathrm{~mL})$ did not observe significant changes $(p>0.05)$.

Wine has been extensively studied as a source of phenolic compounds and adjuvant therapy for various diseases [1], but there are no in vitro studies investigating the specific effect of wine in glucose uptake. Habib and Othman [5] in a study with diabetic patients and Rhaphanus sativa extract, observed that glucose uptake by erythrocytes of diabetic patients were decreased with increasing the glucose. This effect was reversed after the addition of $50 \mu \mathrm{L}$ from the extract mentioned.

\section{Effect of wine on osmotic fragility of erythrocytes}

Hypotonic concentrations of $\mathrm{NaCl}$ induced progressive lyses on the erythrocytes, and previous incubation of erythrocytes for 24 hours with fructose (30 and $100 \mathrm{mM}$ ) caused a significant increase $(p<0.05)$ in cell lyses when compared to erythrocytes exposed to fructose $5 \mathrm{mM}$ (Figure 4A). Red wine at different volumes, partially suppressed fructose-induced hemolysis (Figure 4B and C). The osmotic fragility test for erythrocytes incubated with glucose showed no significant differences $(p>0.05)$ (data not shown).

\section{B}

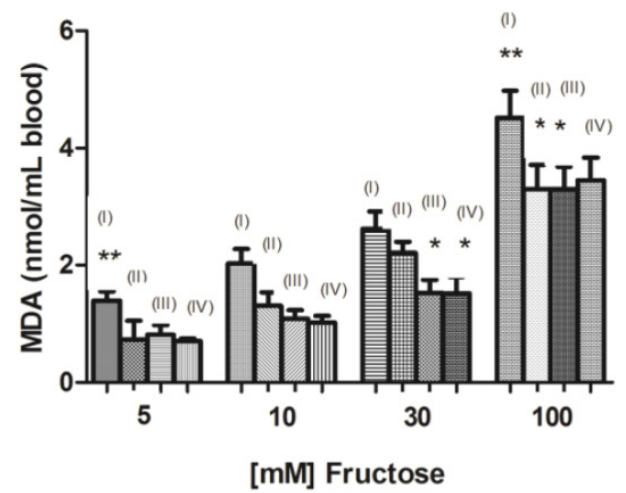

Figure 2: Lipid peroxidation in erythrocytes incubated with different concentrations of glucose (A) or fructose (B) in presence or absence of wine. Tubes incubated only glucose or fructose (I); tubes incubated with glucose or fructose and $0.075 \mathrm{~mL}$ of wine (II); tubes incubated with glucose or fructose and $0.15 \mathrm{~mL}$ of wine (III); tubes incubated with glucose or fructose and $0.225 \mathrm{~mL}$ of wine (IV). * Significant at $p<0.05$, compared with untreated erythrocytes (without addition of wine); ** significant at $p<0.05$, Glucose $5 \mathrm{mM}$ vs Glucose $100 \mathrm{mM}$; Fructose $5 \mathrm{mM}$ vs Fructose $100 \mathrm{mM}$ incubated only glucose or fructose. Values are means \pm SD. 
A

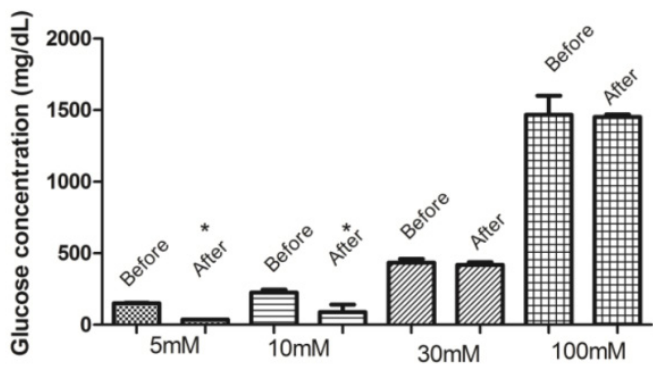

B

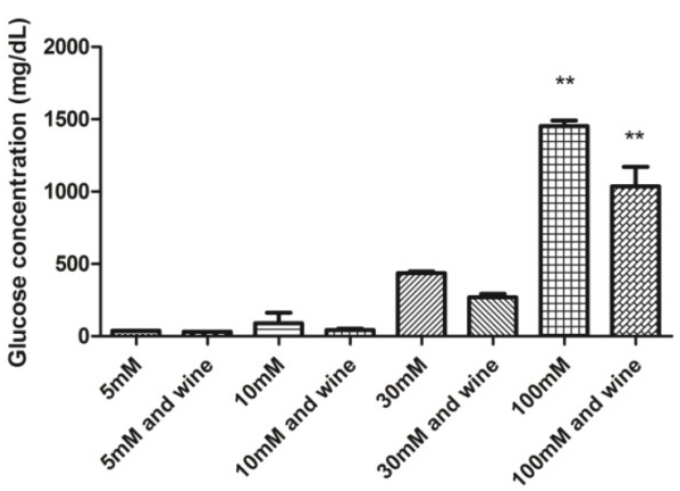

Figure 3: Glucose concentration in erythrocytes before and after incubation with different glucose concentrations (5, 10, 30, and $100 \mathrm{mM}$ ) for 24 hours (A). Glucose concentration in erythrocytes after incubation with different glucose concentrations and $0.075 \mathrm{~mL}$ of wine for 24 hours (B). * Significant at $p<0.05$, compared to erythrocytes before incubation for 24 hours; $* *$ significant at $p<0.05$, compared with untreated erythrocytes (without addition of wine). Values are means \pm SD.
Erythrocytes are constantly exposed to reactive oxygen species and this can be enhanced by hyperglycemia. A research carried out by Soares et al, [13] indicate that patients with uncontrolled diabetes are more sensitive to osmotic shock than from patients with controlled diabetes and control subjects in relation to increased production of free radicals in vivo. As previously discussed the oxidation of erythrocytes has been extensively studied as a model of oxidative damage to biomembranes, since the free radicals attack erythrocyte membranes, oxidizing lipids and proteins. These alterations in membrane structure can subsequently cause hemolysis [42].

The present study shows that erythrocytes exposed to high concentrations of fructose have increased susceptibility to osmotic lysis, which was also accompanied by an increase of lipid peroxidation. This was not observed in erythrocytes incubated with glucose, since these have not had a significant increase in osmotic fragility. The addition of different volumes of red wine in erythrocytes incubated with the fructose were also able to reduce the osmotic fragility in erythrocyte incubated with 30 and $100 \mathrm{mM}$ fructose. This is interesting because it has been shown that ethanol can increase the rate of hemolysis by decreasing the hydrophobic force, which decreases the membrane stability [46]. So we can say that the polyphenols present in large quantities in wine were able to overcome this denaturing effect of ethanol, and also reducing the osmotic fragility caused by high concentrations of fructose.

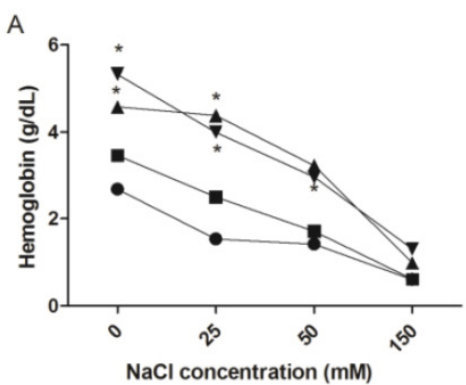

- Fructose $5 \mathrm{mM}$

- Fructose $10 \mathrm{mM}$

- Fructose $30 \mathrm{mM}$

F Fructose $100 \mathrm{mM}$

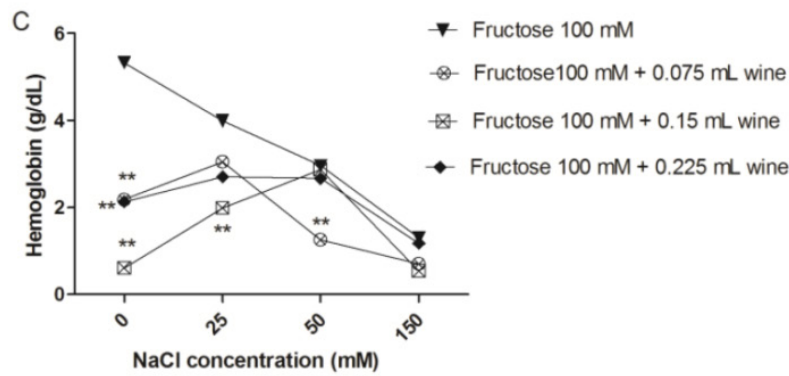

Figure 4: Osmotic fragility test show hemoglobin levels in supernatant of erythrocytes incubated with different fructose concentrations, in presence or absence of wine for $24 \mathrm{~h}$, submitted at decreasing $\mathrm{NaCl}$ concentration hypotonic for $30 \mathrm{~min}$ at $37^{\circ} \mathrm{C}$. Erythrocytes incubated with different fructose concentrations (A). Erythrocytes incubated with $30 \mathrm{mM}$ fructose and different volumes of wine (B). Erythrocytes incubated with $100 \mathrm{mM}$ fructose and different volumes of wine(C). * Significant at $p<0.05$, compared with erythrocytes incubated with $5 \mathrm{mM}$; ** significant at $p<0.05$, compared with erythrocytes treated with fructose (without addition of wine). Values are means \pm SD.

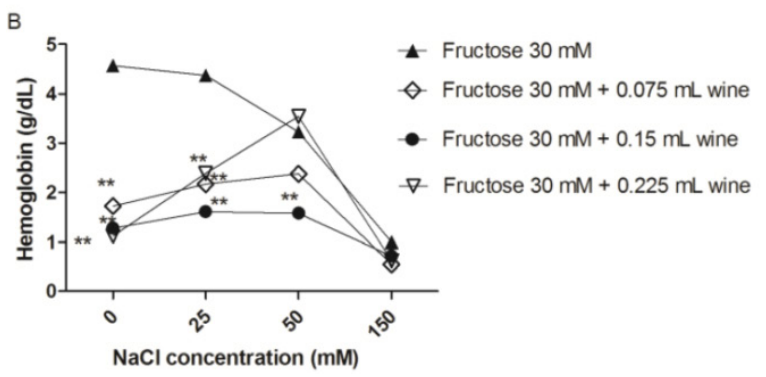


Martínez et al, [41] demonstrated that grape epicatechin stabilize the membrane through a decrease in lipid fluidity, blocking the access of the peroxyl radical to erythrocyte membranes, which may contribute to their ability to inhibit oxidative hemolysis. However, we believe that the antioxidant activity of red wine may be assigned to the group of polyphenols present in this drink, and not any specific compound. The effect of wine in hemolysis was also confirmed by Tedesco et al, [42] in a study on the antioxidant effect of extract of red wine aged in oak barrel with a high level of polyphenols on red blood cells in vitro. They also noted the decrease in osmotic fragility of erythrocytes incubated with $20 \mu \mathrm{L}$ of extract of red wine aged in oak barrel.

\section{Conclusions}

The Tannat red wine produced in Itaqui (RS Brazil) showed high levels of bioactive compounds and high total polyphenols content, as well as a good antioxidant capacity. The wine was also able to attenuate oxidative stress in erythrocytes incubated with glucose or fructose. We believe that the climatic conditions of the region may be the key to explain the results of this study, aiming for the importance of geographical origin as a factor that indirectly acts on the beneficial health effects, quality and the need to encourage the production of wines from this region, giving them their own identity.

\section{Acknowledgements}

The authors wish to acknowledge the UNIPAMPA (Universidade Federal do Pampa), FAPERGS (Fundação de Amparo a Pesquisa do Estado do Rio Grande do Sul), CAPES (Coordenação de Aperfeiçoamento de Pessoal de Nível Superior) and CNPq (Conselho Nacional de Desenvolvimento Científico e Tecnológico) for their financial support. We also thank Campos de Cima Winery (Itaqui, RS), who kindly donated samples of Tannat red wine (2006 vintage).

\section{Competing Interests}

The authors have declared that no competing interest exists.

\section{References}

1. Rodrigo R, Miranda A, Vergara L. Modulation of endogenous antioxidant system by wine polyphenols in human disease. Clin Chim Acta. 2011; 412:410-24.

2. Halliwell B, Aeschbach R, Lölinger J, et al. The characterization on antioxidants. Food Chem Toxicol. 1995; 33:601-17.

3. Brito VB, Folmer V, Soares JCM, et al. Long-term sucrose and glucose consumption decreases the $\delta$-aminolevulinate dehydratase activity in mice. $\mathrm{Nu}$ trition. 2007; 23: 818-26.

4. Brito VB, Rocha JBT, Puntel GO, et al. Inhibition of $\delta$-aminolevulinate dehydratase is not closely related to the development of hyperglycemia in alloxan-induced diabetic mice. Exp Toxicol Pathol. 2011; 63: 443-51.
5. Habib SA, Othman EM. In vitro upregulation of erythrocytes glucose uptake by Rhaphanus sativa extract in diabetic patients. Biochimie. 2012; 94:1206-12.

6. Salgueiro ACF, Leal CQ, Bianchini MC, et al. The influence of Bauhinia forficata Link subsp. pruinosa tea on lipid peroxidation and non-protein $\mathrm{SH}$ groups in human erythrocytes exposed to high glucose concentrations. J Ethnopharmacol. 2013; 148(1): 81-7.

7. Montilla P, Barcos M, Muñoz MC, et al. Protective effect of Montilla-Moriles appellation red wine on oxidative stress induced by streptozotocin in the rat. J Nutr Biochem. 2004; 15:688-93.

8. Cimino F, Sulfaro V, Trombetta D, et al. Radical-scavenging capacity of several Italian red wine. Food Chem. 2007; 103:75-81.

9. Renaud S, De Longeril M. Wine, alcohol, platelets, and the French paradox for coronary heart disease. Lancet. 1992; 339:1523-6.

10. Withehead TP, Robinson D, Allaway S, et al. Effect of Red Wine Ingestion on the Antioxidant Capacity of Serum. Clin Chem. 1995; 41:32-5.

11. Napoli R, Cozzolino D, Guardasole V, et al. Red wine consumption improves insulin resistance but not endothelial function in type 2 diabetic patients. Metabolism. 2005; 54:306-13.

12. Gabriel D, Pivetta L, Folmer V, et al. Human erythrocyte $\delta$-aminolevulinate dehydratase inhibition by monosaccharides is not mediated by oxidation of enzyme sulfhydryl groups. Cell Bioll Int. 2005; 29(8): 669-74.

13. Soares JCM, Folmer V, Rocha JBT, et al. Ebselen exhibits glycation-inhibiting properties and protects against osmotic fragility of human erythrocytes in vitro. Cell Biol Int. 2014; 38(5):625-30.

14. WHO. Global status report on alcohol and health. World Health Organization. 2011. ISBN 978924156415 .

15. Ohkawa $\mathrm{H}$, Ohishi $\mathrm{H}$, Yagi $\mathrm{K}$. Assay for lipid peroxide in animal tissues by thiobarbituric acid reaction. Anal Biochem. 1979; 95:351-58.

16. Fernandez AA, Fink NE. Red blood cell osmotic fragility confidence intervals: definition by application of a mathematical model. Clin Chem Lab Med. 2000; 38:433-36.

17. Singleton VL, Rossi JA Jr. Colorimetry of total phenolics with phosphomolybdic-phosphotungstic acid reagents. Am J Enol Viticult. 1965; 16:144-58.

18. Lee DH, Francis FJ. Standardization of Pigment Analyses in Cranberries. HortScience. 1972; 7:83-4.

19. Quirós AR, López-Hernandéz J, Ferraces-Casais P, et al. Analysis of non -anthocyanin phenolic compounds in wine samples using high performance liquid chromatography with ultraviolet and fluorescence detection. J Sep Sci. 2007; 30:1262-6.

20. Faustini RS, Sobrattee S, Edel AL, et al. Comparative analysis of the phenolic content of selected Chilean, Canadian and American Merlot red wines. Mol Cell Biochem. 2003; 249:11-9.

21. Fanzone M, Peña-Neira A, Jofré V, et al. Phenolic Characterization of Malbec Wines from Mendoza Province (Argentina). J Agric Food Chem. 2010; 58:2388-97.

22. Seruga M, Novak I, Jakobek L. Determination of polyphenols content and antioxidant activity of some red wines by differential pulse voltammetry, HPLC and spectrophotometric methods. Food Chem. 2011; 124:1208-16.

23. Brand-Williams W, Cuvelier ME, Berset C. Use of a free radical method to evaluate antioxidant activity. LWT - Food Sci Technol. 1995; 28:25-30.

24. Boido E, Alcade-Eon C, Carrau F, et al. Aging Effect on the Pigment Composition and Color of Vitis vinifera L. cv. Tannat Wines. Contribution of the Main Pigment Families to Wine Color. J Agric Food Chem. 2006; 54:6692-6704.

25. Zocche RGS. 2009. Potencial enológico de uvas Tannat, Cabernet Sauvignon e Merlot produzidas no município de Bagé - RS. Ph.D. Thesis, Federal University of Pelotas, Pelotas, Brazil.

26. McRae JM, Schulkin A, Kassara S, et al. Sensory Properties of Wine Tannin Fractions: Implications for In-Mouth Sensory Properties. J Agric Food Chem. 2013; 61:719-27.

27. McRae JM, Dambergs RG, Kassara S, et al. Phenolic Compositions of 50 and 30 Year Sequences of Australian Red Wines: The Impact of Wine Age. J Agric Food Chem. 2012; 60:10093-10102.

28. Freitas DM. Variação dos compostos fenólicos e de cor dos vinhos de uvas (Vitis vinífera) tintas em diferentes ambientes. PhD Thesis, Federal University of Santa Maria, Santa Maria, Brazil. 2006.

29. Kennedy JA, Saucier C, Glories Y. Grape and wine phenolics: history and perspective. Am J Enol Viticult. 2006; 57:239-48

30. Fanzone M, Peña-Neira A, Gil M, et al. Impact phenolic and polysaccharidic composition commercial value of Argentinean Malbec and Cabernet Sauvignon wines. Food Res Int. 2012; 45:402-14.

31. Medina I, Undeland I, Larsson K, et al. Activity of caffeic acid in different fish lipid matrices: A review. Food Chem. 2012; 131:730-40.

32. Gris EF, Ferreira EA, Falcão LD, et al. Caffeic acid copigmentation of anthocyanins from Cabernet Sauvignon grape extracts in model systems. Food Chem. 2007; 100:1289-96.

33. Rocha HA, Guerra NB. Polifenóis em vinhos tintos: fatores envolvidos, propriedades funcionais e biodisponibilidade. Revista Iberoamericana de Tecnología Postcosecha. 2008; 9(2):93-105.

34. Souto AA, Carneiro MC, Sefrin M, et al. Determination of trans-resveratrol concentrations in Brazilian red wines by HPLC. J Food Compos Anal. 2001; 14:441-5.

35. Szkudelska K, Szkudelski T. Resveratrol, obesity and diabetes. Eur J Pharmacol. 2010; 635:1-8. 
36. Venturini CD, Merlo S, Souto AA, et al. Resveratrol and red wine function as antioxidants in the central nervous system without cellular proliferative effects during experimental diabetes. Oxid Med Cell Longev. 2010; 3:434-41.

37. Guerra CC, Mandelli F, Tonietto J, et al. Conhecendo o essencial sobre uvas e vinhos. Embrapa uva e vinho. 2009; 48:1-69.

38. [Internet] Hackbart E. http://www.metsul.com/secoes/visualiza.php? cod subsecao $=47 \&$ cod texto $=464$.

39. Melo EA, Lima VLAG, Maciel MIS, et al. Teores de polifenóis, ácido ascórbico e carotenóides totais em frutas e hortaliças usualmente consumidas. Braz J Food Technol. 2006; 9: 89-94.

40. Granato D, Katayama FCV, Castro IA. Phenolic composition of South American red wines classified according to their antioxidant activity, retail price and sensory quality. Food Chem. 2011; 129:366-73.

41. Martínez V, Ugartondo V, Vinardell MP, et al. Grape epicatechin conjugates prevent erythrocyte membrane protein oxidation. J Agric Food Chem. 2012; 60:4090-5.

42. Tedesco I, Russo M, Russo P, et al. Antioxidant effect of red wine polyphenols on red blood cells. J Nutr Biochem. 2000; 11:114-9.

43. Wolff SP, Dean RT. Glucose autoxidation and protein modification - the potential role of 'autoxidative glycosylation' in diabetes. Biochem J. 1987; 245:243-250.

44. Marar T. Amelioration of glucose induced hemolysis of human erythrocytes by vitamin E. Chem-Biol Interac. 2011; 193:149-53.

45. Vahalkar GS, Haldankar VA. RBC membrane composition in insulin dependent diabetes mellitus in context of oxidative stress. Indian J Clin Biochem. 2008; 23:223-6.

46. Tyulina OV, Huenelman MJ, Prokopieva VD, et al. Does ethanol metabolism affect erythrocyte hemolysis? Biochim Biophys Acta. 2000; 1535:69-77. 